TI 2014-124/VIII

Tinbergen Institute Discussion Paper

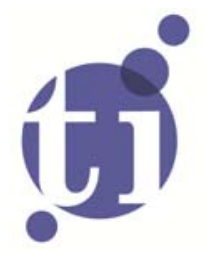

\title{
Renewable Energy and Negative Externalities: The Effect of Wind Turbines on House Prices
}

\author{
Martijn I. Dröesa
}

Hans R.A. Koster

a Faculty of Economics and Business Administration, VU University Amsterdam, Faculty of Economics and Business, University of Amsterdam, and the Amsterdam School of Real Estate, the Netherlands;

b Faculty of Economics and Business Administration, VU University Amsterdam, and Tinbergen Institute, the Netherlands. 
Tinbergen Institute is the graduate school and research institute in economics of Erasmus University Rotterdam, the University of Amsterdam and VU University Amsterdam.

More TI discussion papers can be downloaded at http://www.tinbergen.nl

Tinbergen Institute has two locations:

Tinbergen Institute Amsterdam

Gustav Mahlerplein 117

1082 MS Amsterdam

The Netherlands

Tel.: +31(0)205251600

Tinbergen Institute Rotterdam

Burg. Oudlaan 50

3062 PA Rotterdam

The Netherlands

Tel.: +31(0)10 4088900

Fax: $+31(0) 104089031$

Duisenberg school of finance is a collaboration of the Dutch financial sector and universities, with the ambition to support innovative research and offer top quality academic education in core areas of finance.

DSF research papers can be downloaded at: http://www.dsf.nl/

Duisenberg school of finance

Gustav Mahlerplein 117

1082 MS Amsterdam

The Netherlands

Tel.: +31(0)20 5258579 


\title{
Renewable Energy and Negative Externalities: The Effect of Wind Turbines on House Prices
}

\author{
By MARTIJN I. DRÖES*,+,‡,o AND HANS R.A. KOSTER ${ }^{\dagger, \S}$
}

This version: 16 September 2014

\begin{abstract}
SUMMARY - In many countries, wind turbines are constructed as part of a strategy to reduce dependence on fossil fuels. In this paper, we measure the external effect of wind turbines on the transaction prices of nearby houses. A unique house price dataset covering the period 1985-2011 is used, including the exact location of all wind turbines built in the Netherlands. We find that house prices within a two kilometer radius of a turbine, after it has been constructed, decrease by about 1.4 to 2.3 percent on average. We find anticipation effects up to three years in advance of the construction of a wind turbine. We provide further evidence that the external costs of a wind turbine are at least 10 percent of its construction cost.
\end{abstract}

JEL-code-R31; Q42; Q15; L94

Keywords - renewable energy; wind turbines; externalities; house prices

\section{Introduction}

The world's primary demand for renewable energy has increased from 1.1 billion tons of oil equivalent (Gtoe) in 1990 to 1.7 Gtoe in 2010 and is expected to grow to 3.1 Gtoe in 2035 (IEA, 2012). The production of clean electricity - either through renewable energy sources or nuclear power - is high on the political agenda of many countries. Besides hydro energy, wind energy is one of the most important sources of renewable energy accounting for 8 percent of renewable electricity production in 2010. Its share in production is expected to increase to 24 percent by 2035 (IEA, 2012).

Wind energy is produced by wind turbines. The number of wind turbines is currently about 225,000 worldwide (GWEC, 2012). At the end of 2012, the total wind power capacity

\footnotetext{
* Corresponding author, e-mail: m.droes@vu.nl. NVM (Dutch Association of Realtors) is gratefully acknowledged for providing the transactions data. We thank Giulia Faggio, Jos van Ommeren, Maurice de Kleijn, and seminar participants at the University of Amsterdam, VU University Amsterdam, Rabobank, CPB, NVM, the AREUEA and ERSA 2014 conferences for useful comments.

† Department of Spatial Economics, Faculty of Economics and Business Administration, VU University Amsterdam, De Boelelaan 1105, 1081 HV Amsterdam, The Netherlands.

‡ Amsterdam Business School, Faculty of Economics and Business, University of Amsterdam, Plantage Muidergracht 12, 1018 TV Amsterdam, The Netherlands.

- Amsterdam School of Real Estate, Jollemanhof 5, 1019 GW Amsterdam.

$\S$ Tinbergen Institute Amsterdam, Gustav Mahlerplein 117, 1082 MS Amsterdam.
} 
was 283,000 megawatt (39 percent of capacity is located in Europe), an increase of 16 percent compared to a year earlier (GWEC, 2012). Some of the wind turbines are placed in large wind parks (wind farms), some of them offshore, but there is also an increasingly large number of turbines located close to urbanized areas, especially in countries with space constraints. Given that wind turbines make noise, reduce the quality of views on open space, and cast shadows on nearby properties, we would expect to see a clear negative economic impact as a result of wind turbine construction. There is indeed substantial anecdotal evidence that homeowners are strongly opposed the construction of wind turbines nearby their own houses, because of proclaimed negative effects on housing value (see e.g. NRC, 2013; Trouw, 2013). However, to date, there is no robust empirical evidence on these external effects.

The aim of this paper is to examine the effect of wind turbines on house prices. We use a highly detailed housing transactions dataset from the Netherlands covering the period 1985 to 2011. Using data on all wind turbines placed in the Netherlands since 1980, we can calculate the distance from every property that is sold to the nearest wind turbine. We employ a difference-in-differences approach to identify the effect of the placement of a wind turbine on the value of nearby properties.

Although literature on this topic is scarce, this is not the first study to examine the effect of wind turbines on property values. Sims et al. (2008) and Carter (2011) investigate the effect of a single wind farm on house prices in the UK and US, respectively. Hoen et al. (2011) examine the effect on house prices of 24 wind farms located in 9 states in the US. All of these studies do not find a statistically significant effect of wind farms on house prices. On the other hand, Ladenburg and Dubgaard (2007) do find evidence that household in Denmark are willing to pay 122 Euros per year to increase the distance of an offshore wind park from 8 to $50 \mathrm{~km}$. Gibbons (2014) finds that house prices are 5 to 6 percent lower within two km of a visible wind park in the UK. Our study also belongs to a broader line of research on the effect of (environmental) externalities (e.g. distance to toxic waste sites, airports, power plants) on house prices.

This study adds to the existing literature in several ways. First, previous studies have predominantly examined the price effect of wind turbine parks. In this paper, we focus on the effect of individual wind turbines. This allow us to accurately measure the effect of distance (to the nearest turbine), the impact of wind turbine characteristics (e.g. height, diameter of the blades, 'shadow' areas, direct view), and the effect of multiple treatments (number of wind turbines). Also, earlier studies have often used a relatively low number of transactions - houses are typically not closely located near wind turbines - and a small number of wind turbines to measure the effect of wind turbines on house prices. This can 
explain the lack of statistically significant results in previous studies. ${ }^{1}$ We circumvent this problem by using about 2.2 million transaction prices and information on all wind turbines that have been constructed in the Netherlands.

Second, we aim to adequately address selection and endogeneity concerns. Wind turbines are not randomly allocated across space. Our difference-in-differences strategy with detailed zip code fixed effects deals with all time-invariant unobserved locational differences. To the extent that there is additional unobserved variation, such as unobserved trends that are correlated with the location of wind turbines, we will check the robustness of our results by including location-specific time trends and by using comparable locations relatively close to wind turbines as control group. Moreover, the Dutch government has recently announced a list of locations where new wind turbines are to be constructed. We show results conditional upon this set of locations. To summarize, our estimation approach allows us to identify the causal effect of wind turbines on house prices.

Finally, we explicitly take into account anticipation and adjustment effects. Many previous studies examine the effect on house prices over a limited period of time (i.e. a maximum of 12 years, we use 26 years) and, consequently, these studies limit the scope of the analysis to the average treatment effect. Only focusing on the average effect likely implies an underestimate if there are anticipation and adjustment effects. The effect of wind turbines on house prices is not necessarily immediate or permanent. For example, one may expect that as soon as the construction of a wind turbine is announced, house prices begin to adjust. Furthermore, because of search and transaction costs, housing markets may need time to adjust to changes in the physical environment (Case-Shiller, 1989; Wheaton, 1990; McMillen and McDonald, 2004). Our estimation strategy and rich dataset allows us to decompose the effect of wind turbines before and after construction.

The results in this paper show that after the construction of the first wind turbine house prices within a two km radius are on average 1.4 percent lower than prices in comparable neighborhoods that have no nearby wind turbines. This is a conservative estimate. The effect is highest 500 to 750 meters from a turbine, -2.6 percent, and there is no statistically significant effect after two $\mathrm{km} .{ }^{2}$ In addition, we find that about three years before the placement of a turbine, house prices are already statistically significantly lower than prices in comparable neighborhoods. Before that, the price effect is statistically insignificant. We do not find strong evidence for adjustment effects the years after the construction of a wind turbine. The effect after five years is -2.3 percent.

\footnotetext{
${ }^{1}$ Hoen et al. (2011), for instance, hypothesizes that there might be effects relatively close to wind turbines - the observations they use are unfortunately predominately located between 1.6 to $4.8 \mathrm{~km}$ from a wind turbine. The average distance to a wind turbine in Carter (2011) is 12 miles. Sims et al. (2008) do have a considerable share of their data that captures the property values within half a mile of a wind turbine, but they only have 120 observations in total.

${ }^{2}$ The effect is, therefore, quite local. As mentioned, this may explain why some previous studies did not find any effect of wind turbines on house prices.
} 
The results in this paper do not imply that we should not construct wind turbines, but that we should be careful where to place those turbines. If wind turbines are placed close to (future) urban areas our findings suggest that the external economic costs of wind turbines are substantial. We calculate that, given a range of assumptions, the external costs of a wind turbine are at least 10 percent of its construction cost.

The remainder of this paper is structured as follows. Section II provides a discussion on renewable energy policy and wind turbines. Section III contains the methodology, which is followed by a description of the data in Section IV. In Section V we report the results and Section VI concludes.

\section{Renewable energy policy and wind turbines}

As a result of the Kyoto Protocol, many countries have set targets to reduce their greenhouse gas emissions. The Kyoto Protocol has been active for the period 2008-2012 and, after the United Nations Framework Convention on Climate Change (UNFCCC) Conference in 2012, it has been extended (in limited form) until 2020. As of 2015 a new protocol will be developed (for a discussion, see IEA, 2013).

The policy focus on sustainable development is reflected in renewable energy policies around the world. In the United States, there are production tax credits to stimulate the production of renewable energy and regulations regarding renewable portfolio standards for electricity suppliers. China aims to produce 15 percent of energy in 2020 using nuclear or renewable energy sources (IEA, 2012). The European Union issued the Renewable Energy Directive in 2009, which stipulates that the renewable energy part of energy consumption is to increase to 20 percent by 2020. The European Union leaves it up to its member states how to achieve this goal (European Commission, 2013).

Many countries have responded to the policy focus on renewable energy by increasing their wind power capacity. China, for instance, aims to increase its wind power capacity from 62 to 200 gigawatts by 2020 (IEA, 2012). Wind power production has been particularly popular in the European Union. Currently, about 39 percent of the wind power capacity is located in the European Union, 26 percent in China, and 20 percent in the United States (IEA, 2012). Although wind power capacity is increasing, at current rates the European member states will not meet their required targets (European Commission, 2013).

In the Netherlands, the country to which our data refer, the goal set by the Renewable Energy Directive is to increase the share of renewable energy to 14 percent (European Commission, 2013). ${ }^{3}$ In 2013, a widely supported agreement was reached (Energy Agreement) to increase the wind power capacity on sea from 1,000 megawatt to 4,450

3 The share of renewable energy in the Netherlands was 2.4 percent in 2005 and 3.8 percent in 2010. For France the target is 23 percent and it is 18 percent for Germany. The target ranges from 11 percent for Luxembourg to 49 percent for Sweden (European Commission, 2013). 
megawatt. Also, the amount of wind power capacity on land needs to increase from 2,160 to 6,000 megawatt (SER, 2013). ${ }^{4}$ Because the current generation wind turbines produce about 3 megawatt per turbine, the increase in wind power capacity on land is equivalent to about 1,280 wind turbines $(1,150$ on sea). Relative to the current stock of about 1,800 onshore wind turbines (100 offshore), this implies a massive increase in the number of turbines. ${ }^{5}$ The question is where to exactly place these turbines, especially those turbines that are to be placed on land, since the Netherlands is a relatively small country in terms of land area and a country with one of the highest population densities in the world.

\section{Empirical methodology}

In this paper, we focus on estimating the average treatment effect after the first wind turbine is constructed within $d \mathrm{~km}$ of a property. A difference-in-differences methodology is ideally suited to estimate this effect. Let $p_{i t}$ be the price of property $i$ in year $t, w_{i t}$ is an indicator variable that equals one in the years (including the year of construction) after the first wind turbine is placed within $d$ kilometers of property $i, v_{i}$ is the treatment versus control group dummy, where the treatment group are those observations within $d$ kilometers of a wind turbine in 2012. The difference-in-differences model we estimate is:

$$
\log p_{i t}=\alpha w_{i t}+\gamma v_{i}+\theta_{t}+\epsilon_{i t}
$$

where $\alpha$ captures the average treatment effect, $\theta_{t}$ captures year (and month) fixed effects, and $\epsilon_{i t}$ is an identically and independently distributed error term. In the empirical section, we assume that $d=2$. To validate this choice, we also investigate whether wind turbines have any measurable effect beyond two km (see equation (4)).

It is important to note that we rely on two sources of identifying variation to measure the treatment effect. First, we compare the price difference of houses within versus outside two $\mathrm{km}$ of a wind turbine. Second, because not all wind turbines are constructed at the same time, we essentially compare price differences of properties in areas that have received a wind turbine with areas that did not yet receive a wind turbine at that particular point in time, but will receive one at a future date.

To control for differences in the housing composition of the control and treatment group, we subsequently estimate the following hedonic model:

$$
\log p_{i t}=\alpha w_{i t}+\gamma v_{i}+\beta x_{i t}+\theta_{t}+\epsilon_{i t}
$$

\footnotetext{
${ }^{4}$ Currently, wind turbines are highly subsidized. The subsidy on wind turbines is equal to the difference in electricity production cost (in euro per $\mathrm{kWh}$ ) and the average price of electricity.

${ }^{5}$ Not all turbines will be placed offshore because constructing turbines at sea is relatively costly. It also requires the construction of an offshore power grid (additional investment).
} 
where $x_{i t}$ is a set of housing attributes including the size of the house, the number of rooms, house type dummies, indicators for garage, garden, maintenance quality, central heating, whether the house is listed as cultural heritage, and construction year dummies.

Wind turbines are not randomly distributed across space. They may for instance be placed in low priced areas, which may lead to a selection effect. This is, however, captured by the treatment group dummy variable $v_{i}$. There may also be other unobserved factors (e.g. zoning regulations) that characterize the treatment area and affect house prices. To the extent that these factors are time invariant, we can control for them by using locationspecific fixed effects:

$$
\log p_{i t}=\alpha w_{i t}+\beta x_{i t}+\eta_{j}+\theta_{t}+\epsilon_{i t}
$$

where $\eta_{j}$ is a fixed effect for location $j$. We measure location at the six-digit (PC6) zip code level. In the Netherlands, PC6 areas encompass about half a street (on average 15 households), which is comparable to a census block in the United States. ${ }^{6}$ In essence, the fixed effects deal with all unobserved time-invariant spatial attributes that may cause the construction of wind turbines and may be correlated with $\epsilon_{i t}$ (Van Ommeren and Wentink, 2012). ${ }^{7}$

One may argue that the current identification strategy does not adequately deal with differences in unobserved local trends (e.g. changes in local building restrictions) that are correlated with the placement of wind turbines. To account for such trends, we also estimate equation (3) using a restricted sample: we compare houses within the treatment area with houses outside the treatment area but within a short distance (three $\mathrm{km}$ ) of a wind turbine in 2012. This will lead to a much smaller sample, but addresses the problem of unobserved time trends. ${ }^{8}$

It may be expected that the effect of wind turbines becomes less pronounced when properties are located further away from a wind turbine. We therefore allow the treatment effect to differ over different distances from the nearest wind turbine:

$$
\log p_{i t}=\sum_{z} \alpha_{z} w_{i t z}+\beta x_{i t}+\eta_{j}+\theta_{t}+\epsilon_{i t}
$$

where $w_{i t z}$ equals one after the first wind turbine is placed and the property is located within the corresponding 250 meter band $z$. In essence, we divide the three $\mathrm{km}$ circle around a wind turbine into different zones, where we use the 2.5 to $3 \mathrm{~km}$ zone as the

\footnotetext{
${ }^{6}$ Note that the control versus treatment group dummy (essentially just a location dummy) is excluded in this specification since it is almost perfectly collinear with the PC6 fixed effects.

${ }^{7}$ The benefit of this particular approach is that we do adequately control for neighborhood and (average) housing quality differences, but we do not lose most of the data as a result of differencing (repeat sales), which may result in sample selection bias (see Gatzlaff and Haurin, 1998).

${ }^{8}$ In the sensitivity analysis, we also show estimates where we control for municipality trends and neighborhood-specific trends. In addition, we experiment with different local control groups.
} 
reference category. The cut-off value for $d$ is determined by examining at which point the effect on house prices $\alpha_{z}$ become statistically insignificant relative to the reference category. This procedure is, therefore, based on the assumption that the price effect for the reference category is zero. We will discuss the validity of this assumption in detail in the empirical results section, Section $\mathrm{V}$.

Finally, we would expect the effect to differ before and after the turbine is constructed. The placement of wind turbines is usually announced some years before construction. It is likely that house prices already incorporate this information, which implies that $\alpha$ may be an underestimate of the causal effect if we do not take into account anticipation effects. On the other hand, it might also be the case that because of search and transaction costs, housing markets may need time to adjust to changes in the physical environment (CaseShiller, 1989; Wheaton, 1990; McMillen and McDonald, 2004; Redfearn, 2009). To account for anticipation and adjustment effects, we therefore estimate the following specification:

$$
\log p_{i t}=\sum_{s=\underline{t}}^{t-1} \alpha_{s} w_{i s}+\sum_{s=t}^{\bar{t}} \alpha_{s} w_{i s}+\beta x_{i t}+\eta_{j}+\theta_{t}+\epsilon_{i t}
$$

where $\underline{t}$ is first year for which we expect anticipation effects, while $\bar{t}$ denotes the last year for which we expect adjustment effects, and $w_{i s}$ equals one when the property is treated in year $s$ and zero otherwise. Hence, the first term on the right hand side captures anticipation effects of wind turbines that will be constructed in the future, whereas the second term captures adjustment effects after the wind turbine has been constructed. We use a window of five years before or after construction, so $\underline{t}=t-5$ and $\bar{t}=t+5$.

\section{Data}

The analysis in this paper is based on two main datasets. The first dataset contains the exact location of all wind turbines in the Netherlands from 1982-2012 and is obtained from www.windstats.nl. For each wind turbine we know the exact location, the axis height, the diameter of the rotor blades, the installed capacity, the manufacturer, and importantly, the construction year. ${ }^{9}$

Table 1 contains the descriptive statistics for the wind turbine dataset. There are 1,898 wind turbines in the Netherlands in 2012. The average axis height is 59 meters, with a minimum of 21 meters and a maximum of 135 meters. The average diameter of the rotor blades is 56 meters. The average capacity is 1.3 megawatts. The construction costs per wind

\footnotetext{
${ }^{9}$ We do not have information about the exact date the construction of the turbine is completed. We only know the construction year. We also do not have information about the announcement date of the construction plan.
} 
TABLE 1 - DESCRIPTIVE STATISTICS: WIND TURBINES

\begin{tabular}{lrrrr}
\hline & \multicolumn{4}{c}{ Full sample } \\
\cline { 2 - 5 } & mean & std. dev. & min & max \\
\hline Axis height $(m)$ & 59.496 & 20.231 & 21.000 & 135.000 \\
Diameter of rotor blades $(m)$ & 55.997 & 21.963 & 11.000 & 127.000 \\
Capacity $(M W)$ & 1.260 & 0.953 & 0.015 & 7.500 \\
Onshore & 0.949 & 0.219 & & \\
Construction year & 2002 & 5.507 & 1982 & 2012 \\
Number of observations & \multicolumn{5}{c}{1,898} \\
\hline Notes: This table contains descriptive statistics on all wind turbines \\
constructed between 1982 and 2012. The axis height and diameter of the \\
rotor blades is only available for respectively 1,793 and 1,893 observations.
\end{tabular}

turbine are about 1.7 million Euros. ${ }^{10} \mathrm{~A}$ typical wind turbine has a life span of 20 years or even longer (if it is properly maintained). About 95 percent of wind turbines are placed on land (96 are offshore). The main manufacturer of wind turbines in the Netherlands is the Danish company Vestas. They produced 1,128 (59.4 percent) of the wind turbines in the Netherlands. ${ }^{11}$ Wind turbines are often owned by Dutch energy companies NUON, Eneco, and Essent.

Figure 1 shows the spatial distribution of wind turbines across the Netherlands. Wind turbines are predominately clustered in Flevoland (27.6 percent), a mostly rural area in the centre of the Netherlands. The early wind turbines were mainly constructed in the northern part of the Netherlands. The northern part is not so urbanized as, for instance, the western part of the Netherlands. In addition, the wind speed - also depicted in Figure 1 - is relatively high in the northern part of the Netherlands. ${ }^{12}$ Other concentrations of wind turbines can be found in the coastal province of Zeeland. More recently, two offshore wind parks have become operational (in 2006 and 2008). These offshore wind parks are located more than ten $\mathrm{km}$ from the shore. In this paper, we will focus on the external effects of wind turbines placed on land.

The second dataset we use in this paper covers about 70 percent of all housing transactions in the Netherlands from 1985-2011 and is obtained from the Dutch Association of Realtors (NVM). For more than two million observations we know the transaction price of each property, as well as a host of housing attributes, such as the size in square meters, the construction year, number of rooms and variables that indicate the presence of a garage,

${ }^{10}$ Construction costs are proportional to the installed capacity of the turbine (as a rule of thumb, about 1325 Euros per kW installed capacity, see ECN, 2008).

${ }^{11}$ This includes the turbines placed by NEG Micon. In 2004, NEG Micon and Vestas merged, which resulted in the creation of one of the largest wind turbine manufacturing companies in the world.

${ }^{12}$ Figure 1 shows the wind at 100 meters above ground level (calculated by KEMA Netherlands B.V. and Geodan IT, 2005). 


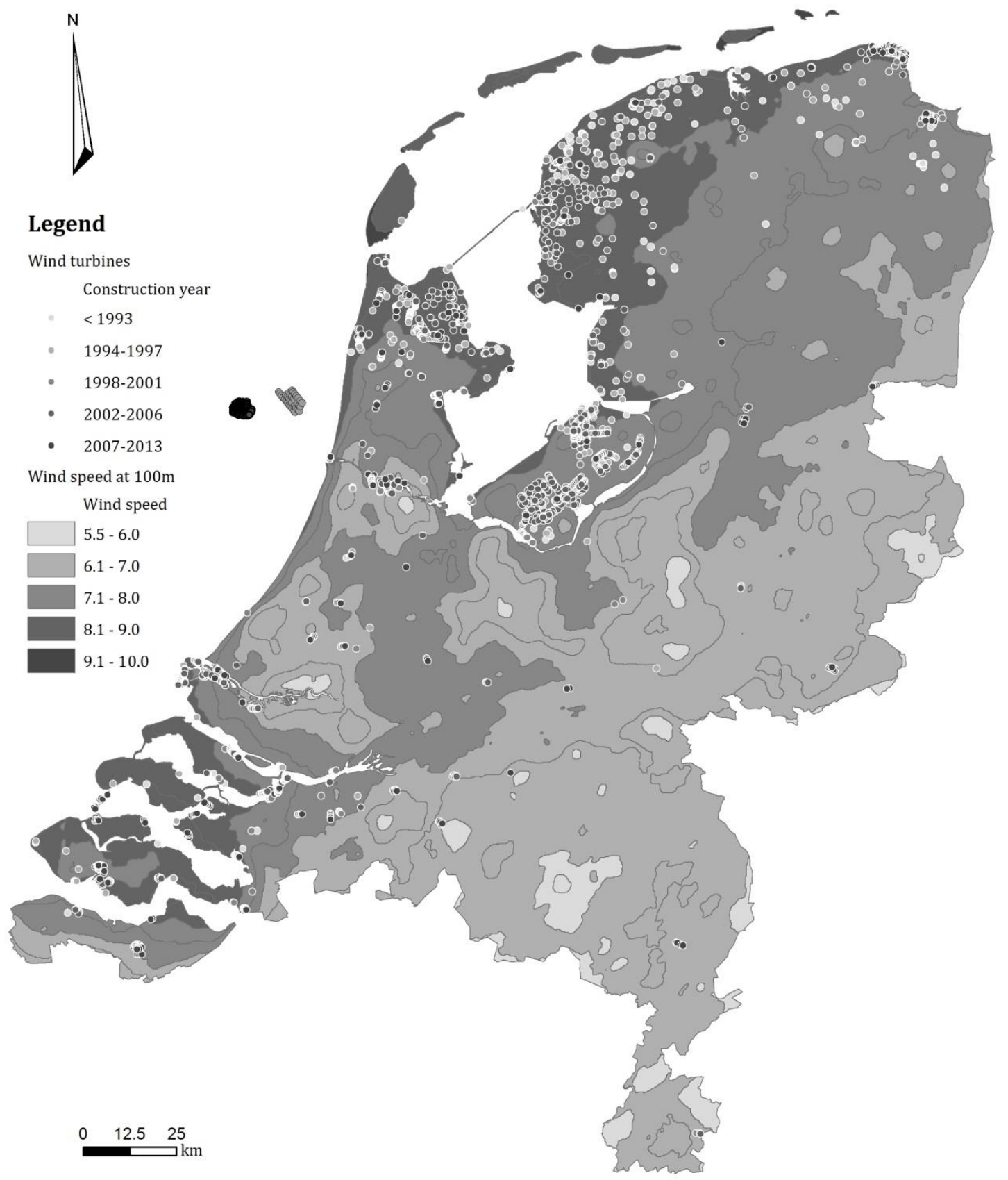

FIGURE 1 - SPATIAL DISTRIBUTION OF WIND TURBINES IN THE NETHERLANDS 
garden and central heating. Because the exact location of each property is known, we can calculate the straight-line distance of each property to the nearest wind turbine.

Figure 2 shows that the number of wind turbines has been steadily increasing since the construction of the first wind turbine in 1982. Before 1990 only 25 wind turbines were constructed. Not surprisingly, the average distance of a property to the nearest wind turbine has been decreasing over the years. The average distance only decreased marginally after 2005 , while the number of wind turbines has increased with 34 percent during the same period.

Table 2 presents descriptive statistics for the housing transactions dataset. 13 The average distance to the nearest wind turbine is about $20.5 \mathrm{~km}$. We consider observations within two $\mathrm{km}$ of a (future) wind turbine as part of the treatment group. Table 2 shows that 6.8 percent of observations (about 150,000 observations) are in the treatment group and 4.1 percent of the housing transactions (about 90,000 observations, 80,000 houses) are located within a two $\mathrm{km}$ radius of a wind turbine after it has been constructed (our main variable of interest).

Table 3 reports the descriptive statistics for observations within versus outside a two $\mathrm{km}$ radius of a wind turbine in 2012 (treatment versus control group). As expected, wind turbines are placed in areas with a relatively low house price (i.e. rural areas). In the regression analysis, any differences in average house prices across locations are captured by the PC6 fixed effects. There are 161,065 unique PC6 areas in our dataset with, on average, 14 transactions per zip code. There are 15,456 PC6 areas for which we only have one transaction ( 0.7 percent of the total number of observations). Given the other differences in housing characteristics between the treatment and control group, it is important to also control for housing characteristics in the empirical analysis. There are, for example, relatively a lot of detached houses and a low share of apartments close to wind turbines.

To gain a better understanding in the different sources of the external effect of wind turbines, it is important to examine the distribution of the observations within a two km radius of a wind turbine after it has been constructed. Figure 3 reports this distribution. There are few observations that are within 500 meter of a wind turbine (about 1.6 percent of the 90,000 transactions). In part, this reflects zoning restrictions. It also implies that the main effect we will be measuring is not the effect of noise. As a rule of thumb, wind turbine noise is typically deemed to be a problem within four to five times the axis height (Dooper et al., 2010). ${ }^{14}$ Since the typical (current generation) of wind turbines have an axis height of

${ }^{13}$ We exclude transactions with prices that are above $€ 1.0$ million or below $€ 25,000$ or a square meter price below $€ 500$ or above $€ 5,000$. Furthermore, we exclude transactions that refer to properties smaller than $25 \mathrm{~m}^{2}$ or larger than $250 \mathrm{~m}^{2}$. These selections comprise less than one percent of the observations.

${ }^{14}$ It turns out that at about 400 to $500 \mathrm{~m}$ distance a turbine makes about 40 to $50 \mathrm{~dB}$ noise, which is about the amount of noise a refrigerator makes. 


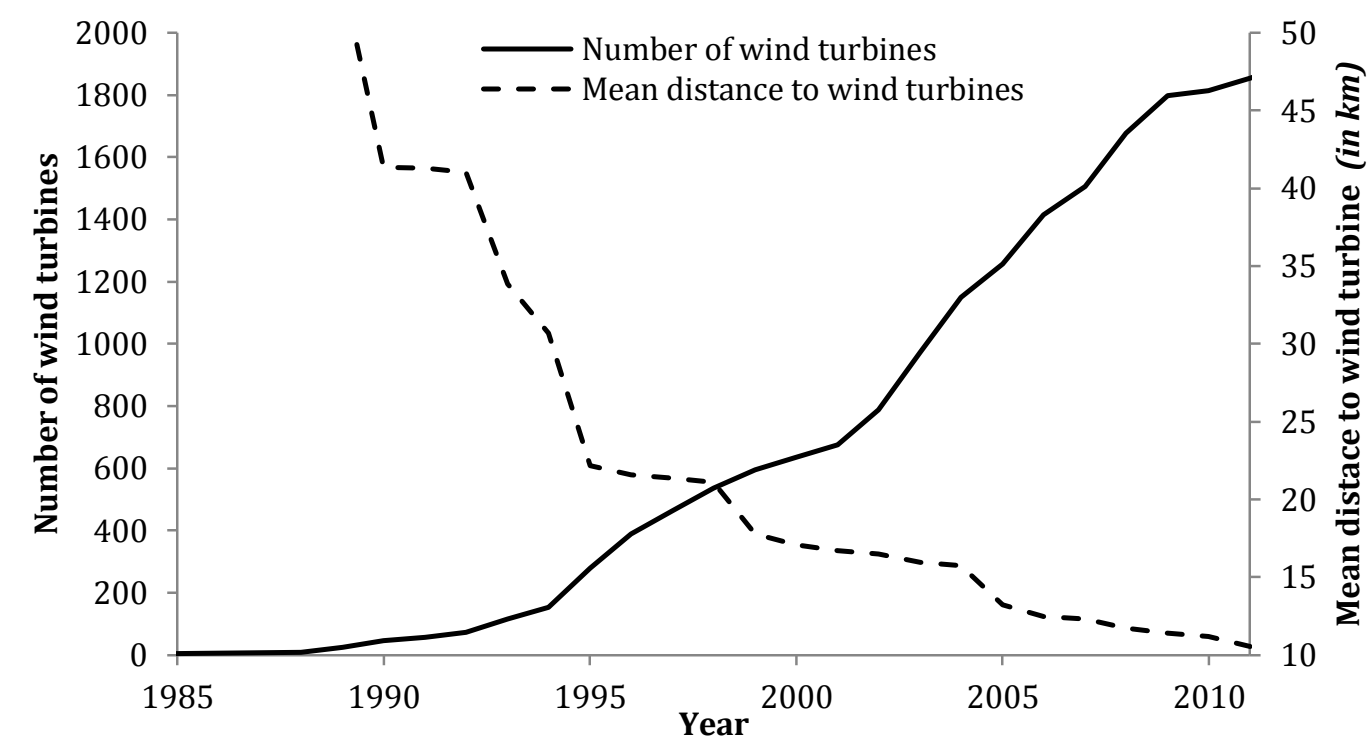

FigURE 2 - NUMBER OF WIND TURBINES IN THE NETHERLANDS

TABLE $2-$ DESCRIPTIVE STATISTICS: Housing TRANSACTIONS

\begin{tabular}{|c|c|c|c|c|}
\hline & mean & std. dev. & $\min$ & $\max$ \\
\hline Price $(€)$ & 193,960 & 114,713 & 25,000 & $1,000,0000$ \\
\hline Price per $\mathrm{m}^{2}(€)$ & 1,654 & 750 & 500 & 5,000 \\
\hline Distance to nearest wind turbine $(\mathrm{km})$ & 20.523 & 27.706 & 0.081 & 315.606 \\
\hline Wind turbine in $2012 \leq 2 \mathrm{~km}$ & 0.068 & 0.251 & & \\
\hline Wind turbine $\leq 2 \mathrm{~km}$ & 0.041 & 0.198 & & \\
\hline Density wind turbines per $\mathrm{km}^{2} \leq 2 \mathrm{~km}$ & 0.006 & 0.040 & 0 & 1.989 \\
\hline Size in $\mathrm{m}^{2}$ & 118.089 & 37.765 & 26.000 & 250.000 \\
\hline Rooms & 4.333 & 1.317 & 0 & 25.000 \\
\hline Apartment & 0.271 & 0.444 & & \\
\hline Terraced & 0.319 & 0.466 & & \\
\hline Semi-detached & 0.281 & 0.449 & & \\
\hline Detached & 0.130 & 0.336 & & \\
\hline Garage & 0.338 & 0.473 & & \\
\hline Garden & 0.652 & 0.476 & & \\
\hline Maintenance quality - good & 0.863 & 0.344 & & \\
\hline Central heating & 0.900 & 0.300 & & \\
\hline Listed (as cultural heritage) & 0.006 & 0.078 & & \\
\hline Construction year $<1945$ & 0.248 & 0.432 & & \\
\hline Construction year 1945-1959 & 0.074 & 0.261 & & \\
\hline Construction year 1960-1970 & 0.161 & 0.368 & & \\
\hline Construction year 1971-1980 & 0.186 & 0.389 & & \\
\hline Construction year 1981-1990 & 0.152 & 0.359 & & \\
\hline Construction year 1991-2000 & 0.130 & 0.337 & & \\
\hline Construction year $\geq 2000$ & 0.049 & 0.216 & & \\
\hline Year of observation & 2002 & 5.896 & 1985 & 2011 \\
\hline Number of observations & & 2,21 & & \\
\hline
\end{tabular}


TABLE 3 - DESCRIPTIVE STATISTICS: TREATMENT VERSUS CONTROL GROUP

\begin{tabular}{|c|c|c|c|c|c|c|c|c|}
\hline & \multicolumn{4}{|c|}{$<2 \mathrm{~km}$ of a wind turbine in 2012} & \multicolumn{4}{|c|}{$>2 \mathrm{~km}$ of a wind turbine in 2012} \\
\hline & mean & std. dev. & $\min$ & $\max$ & mean & std. dev. & $\min$ & $\max$ \\
\hline Price $(€)$ & 180,183 & 102,471 & 25,865 & $1,000,000$ & 194,959 & 115,486 & 25,000 & $1,000,000$ \\
\hline Price per $\mathrm{m}^{2}(€)$ & 1,552 & 659 & 500 & 5,000 & 1,661 & 756 & 500 & 5,000 \\
\hline Size in $\mathrm{m}^{2}$ & 116.075 & 35.597 & 27.000 & 250.000 & 118.235 & 37.913 & 26.000 & 250.000 \\
\hline Rooms & 4.361 & 1.240 & 0 & 24.000 & 4.331 & 1.323 & 0 & 25.000 \\
\hline Apartment & 0.197 & 0.398 & & & 0.276 & 0.447 & & \\
\hline Terraced & 0.367 & 0.482 & & & 0.315 & 0.465 & & \\
\hline Semi-detached & 0.284 & 0.451 & & & 0.280 & 0.449 & & \\
\hline Detached & 0.152 & 0.359 & & & 0.128 & 0.334 & & \\
\hline Garage & 0.322 & 0.467 & & & 0.339 & 0.473 & & \\
\hline Garden & 0.708 & 0.455 & & & 0.647 & 0.478 & & \\
\hline Maintenance quality - good & 0.856 & 0.352 & & & 0.863 & 0.343 & & \\
\hline Central heating & 0.885 & 0.320 & & & 0.901 & 0.299 & & \\
\hline Listed (as cultural heritage) & 0.005 & 0.072 & & & 0.006 & 0.078 & & \\
\hline Construction year $<1945$ & 0.276 & 0.447 & & & 0.246 & 0.430 & & \\
\hline Construction year 1945-1959 & 0.068 & 0.251 & & & 0.074 & 0.262 & & \\
\hline Construction year $1960-1970$ & 0.143 & 0.350 & & & 0.163 & 0.369 & & \\
\hline Construction year 1971-1980 & 0.167 & 0.373 & & & 0.187 & 0.390 & & \\
\hline Construction year 1981-1990 & 0.153 & 0.360 & & & 0.152 & 0.359 & & \\
\hline Construction year 1991-2000 & 0.139 & 0.346 & & & 0.130 & 0.336 & & \\
\hline Construction year $\geq 2000$ & 0.055 & 0.228 & & & 0.049 & 0.215 & & \\
\hline Year of observation & 2002 & 5.839 & 1985 & 2011 & 2002 & 5.900 & 1985 & 2011 \\
\hline Number of observations & \multicolumn{4}{|c|}{149,939} & \multicolumn{4}{|c|}{$2,069,149$} \\
\hline
\end{tabular}




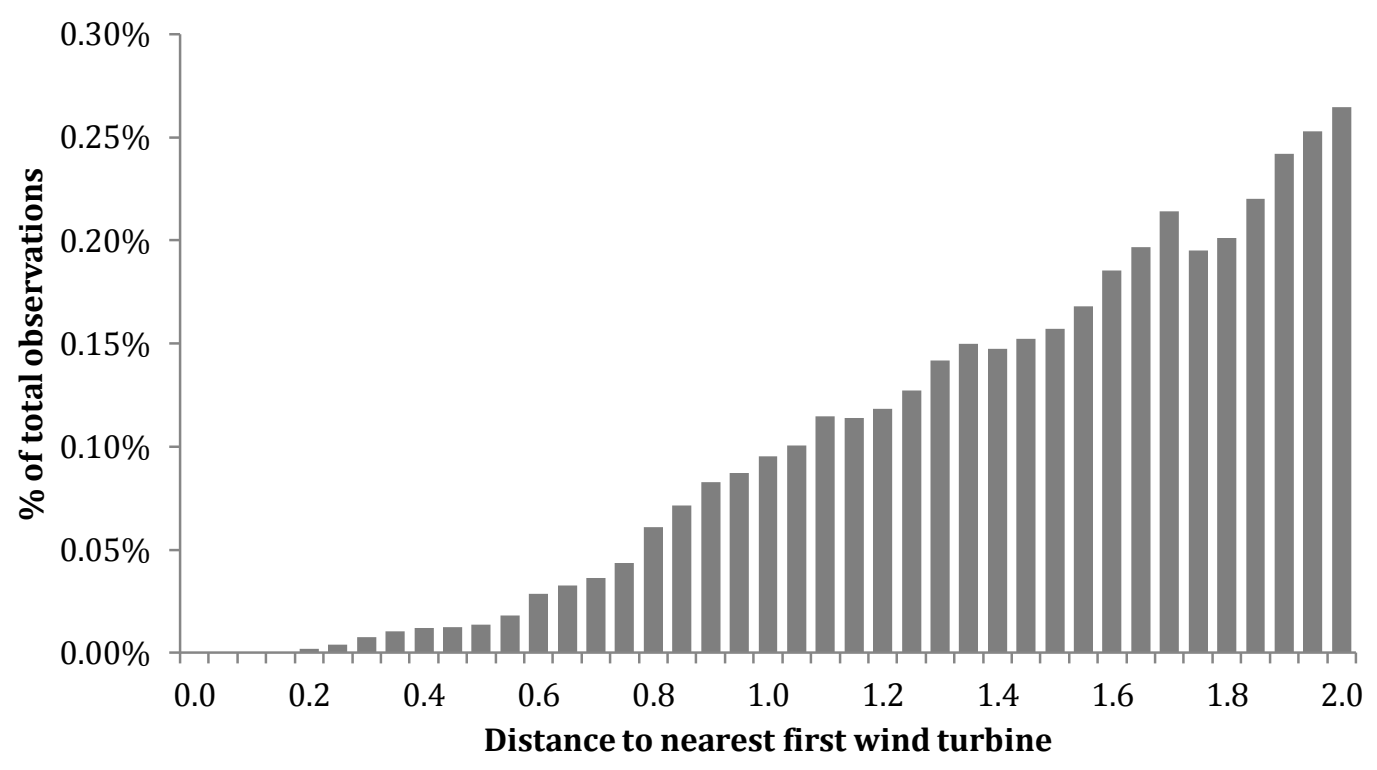

FIGURE 3 - DiSTANCE TO WIND TURBINES WITHIN TWO KM, AFTER CONSTRUCTION

about 100 meters (note that the average is much lower), the effect of noise on house prices should predominately occur within a 500 meter radius. ${ }^{15}$

A further issue is the effect of shadow and flickering of the blades on house prices. As a rule of thumb, this effect is only regarded as a problem within twelve times the rotor diameter (Dooper et al., 2010).16 The typical rotor diameter of current wind turbines is 90 meters (again, the average is much lower), which suggests that this effect is mainly relevant within about one km of a turbine. If a turbine creates more than about six hours of shadow, it is required to have a 'stand-still' feature installed to reduce the amount of flickering (Dooper et al., 2010). As a result, we argue that the shadow effect is not the main driver behind the estimated decrease in property values after the construction of a wind turbine. Nevertheless, we will report some results about the price effect of shadow in Section V.E.

We argue that we predominantly measure the effect of direct and indirect views of wind turbines. The effect of shadow and noise mainly occurs within a 0.5 to $1.0 \mathrm{~km}$ radius from a wind turbine. Figure 3 suggest that the majority of observations are, however, outside a one $\mathrm{km}$ radius. Outside this one $\mathrm{km}$ radius the effect on house prices is probably a view effect. Because the Netherlands is a flat country, a wind turbine is most likely highly visible from many different locations close to a wind turbine, although the direct view from a house might be obstructed by other buildings. Because households may frequently visit other

15 We do not argue that noise is not a problem for those households living close to a wind turbine, but just that we do not have enough data to identify its effect on house prices.

${ }^{16}$ A typical turbine creates flickering at a rate of $1.5 \mathrm{~Hz}$. Flickering between 2.5 and $14 \mathrm{~Hz}$ is considered to be a health risk (Dooper et al., 2010). 
parts of the neighborhood (e.g. for shopping, to take a walk), we would expect that the 'indirect' view effect is an important determinant of the decrease in house value as a result of wind turbine construction. We will show some results about the effect of direct versus indirect view on house prices in the empirical analysis.

\section{Results}

The results section is organized as follows. We first present our baseline estimates for the average treatment effect. We then elaborate on the exact radius of the treatment effect and examine whether anticipation and adjustment effects are important (Sections V.B and V.C respectively). Section V.D checks robustness of the results regarding different identifying assumptions. Then, we look more closely at further heterogeneity in the treatment effect in Section V.E. Finally, we present a counterfactual analysis in Section V.F about the total loss in house value as a result of the construction of wind turbines in the Netherlands.

\section{A. Average treatment effect}

Table 4 contains the regression estimates based on equations (1) to (5). ${ }^{17}$ Column (1) shows the regression estimates of equation (1), the standard difference-in-differences (DID) model. The results in column (1) suggest that areas within a two km distance from a wind turbine (after construction) have on average 6.8 percent lower house prices in comparison with areas that do not have a wind turbine located nearby. In column (2) we add housing characteristics as additional control variables. The treatment effect is very similar in magnitude ( -6.3 percent) as the previous estimate. The results also suggest that wind turbines are placed at locations where house prices are 2.8 percent lower. This selection effect together with the treatment effect contributes to the idea that wind turbines have a strong effect on house prices. This price effect, however, is not necessarily causal. In column (3), we add PC6 fixed effects (see equation (3)). By controlling for all unobserved timeinvariant locational attributes, the effect of wind turbines is much smaller. According to this model, the treatment effect is -1.2 percent.

Still, there might be other unobserved traits, like changes in zoning regulations, which might affect the estimates. Consequently, we examine house prices of the treatment group versus a local control group: we only select observations that are within three $\mathrm{km}$ of a wind turbine in 2012. The results are reported in column (4). House prices decrease by 1.4 percent after a wind turbine is constructed. This is most likely a conservative estimate for at least two reasons. First, when there are effects of wind turbines beyond two kilometers, the estimated coefficient will be an underestimate. We will discuss the geographical extent of the negative external effects of wind turbines in Section V.B. Second, when anticipation

${ }^{17}$ We use clustered standard errors at the 4-digit zip code level. We experimented with standard errors clustered at either the 6-digit zip code, municipality, or wind turbine ID level. Our conclusions remain the same. 
TABLE 4 - BASELINE REGRESSION RESULTS: THE EFFECT OF WIND TURBINES ON HOUSE PRICES (Dependent variable: The logarithm of house price)

\begin{tabular}{|c|c|c|c|c|c|c|}
\hline & (1) & (2) & (3) & $(4)$ & (5) & (6) \\
\hline & $\begin{array}{l}\text { Classical } \\
\text { DID }\end{array}$ & $\begin{array}{c}\text { Housing } \\
\text { characteristics }\end{array}$ & $\begin{array}{l}\text { PC6 fixed } \\
\text { effects }\end{array}$ & $\begin{array}{c}\text { Control group } \\
2-3 \mathrm{~km}\end{array}$ & $\begin{array}{l}\text { Geographical } \\
\text { extent }\end{array}$ & $\begin{array}{l}\text { Dynamic } \\
\text { response }\end{array}$ \\
\hline Wind turbine $\leq 2 \mathrm{~km}$ & $\begin{array}{c}-0.0682^{* * *} \\
(0.0252)\end{array}$ & $\begin{array}{c}-0.0626^{* * *} \\
(0.0190)\end{array}$ & $\begin{array}{c}-0.0123^{* *} \\
(0.005)\end{array}$ & $\begin{array}{c}-0.0144^{* *} \\
(0.006)\end{array}$ & See Fig.4 & See Fig. 5 \\
\hline Wind turbine in $2012 \leq 2 \mathrm{~km}$ & $\begin{array}{c}-0.0365 \\
(0.0225)\end{array}$ & $\begin{array}{c}-0.0284^{* *} \\
(0.0142)\end{array}$ & & & & \\
\hline House size $(\log )$ & & $\begin{array}{c}0.8566^{* * *} \\
(0.0104)\end{array}$ & $\begin{array}{c}0.5961^{* * *} \\
(0.0042)\end{array}$ & $\begin{array}{c}0.5762^{* * *} \\
(0.0088)\end{array}$ & $\begin{array}{c}0.5762^{* * *} \\
(0.0088)\end{array}$ & $\begin{array}{c}0.5764^{* * *} \\
(0.0088)\end{array}$ \\
\hline Rooms & & $\begin{array}{c}0.0076^{* * *} \\
(0.0014)\end{array}$ & $\begin{array}{c}0.0161^{* * *} \\
(0.0003)\end{array}$ & $\begin{array}{c}0.0195^{* * *} \\
(0.0009)\end{array}$ & $\begin{array}{c}0.0195^{* * *} \\
(0.0009)\end{array}$ & $\begin{array}{c}0.0195^{* * *} \\
(0.0009)\end{array}$ \\
\hline Terraced & & $\begin{array}{c}-0.1142^{* * *} \\
(0.0114)\end{array}$ & $\begin{array}{c}0.0396^{* * *} \\
(0.0036)\end{array}$ & $\begin{array}{c}0.0511^{* * *} \\
(0.0084)\end{array}$ & $\begin{array}{c}0.0512^{* * *} \\
(0.0084)\end{array}$ & $\begin{array}{c}0.0510^{* * *} \\
(0.0084)\end{array}$ \\
\hline Semi-detached & & $\begin{array}{c}-0.0743^{* * *} \\
(0.0121)\end{array}$ & $\begin{array}{c}0.1004^{* * *} \\
(0.0036)\end{array}$ & $\begin{array}{c}0.1044^{* * *} \\
(0.0080)\end{array}$ & $\begin{array}{c}0.1045^{* * *} \\
(0.0080)\end{array}$ & $\begin{array}{c}0.1043^{* * *} \\
(0.0080)\end{array}$ \\
\hline Detached & & $\begin{array}{c}0.0950^{* * *} \\
(0.0142)\end{array}$ & $\begin{array}{c}0.3258^{* * *} \\
(0.0043)\end{array}$ & $\begin{array}{c}0.3223^{* * *} \\
(0.0103)\end{array}$ & $\begin{array}{c}0.3223^{* * *} \\
(0.0103)\end{array}$ & $\begin{array}{c}0.3222^{\text {*** }} \\
(0.0103)\end{array}$ \\
\hline Garage & & $\begin{array}{c}0.0956^{* * *} \\
(0.0032)\end{array}$ & $\begin{array}{c}0.0987^{* * *} \\
(0.0010)\end{array}$ & $\begin{array}{c}0.1046^{* * * *} \\
(0.0022)\end{array}$ & $\begin{array}{c}0.1046^{* * *} \\
(0.0022)\end{array}$ & $\begin{array}{c}0.1046^{* * *} \\
(0.0022)\end{array}$ \\
\hline Garden & & $\begin{array}{c}-0.0016 \\
(0.0024)\end{array}$ & $\begin{array}{c}0.0069^{* * *} \\
(0.0020)\end{array}$ & $\begin{array}{c}0.0061 \\
(0.0049)\end{array}$ & $\begin{array}{c}0.0061 \\
(0.0049)\end{array}$ & $\begin{array}{c}0.0061 \\
(0.0049)\end{array}$ \\
\hline Maintenance quality & & $\begin{array}{c}0.1070^{* * *} \\
(0.0027)\end{array}$ & $\begin{array}{c}0.1000^{* * *} \\
(0.0009)\end{array}$ & $\begin{array}{c}0.1036^{* * *} \\
(0.0022)\end{array}$ & $\begin{array}{c}0.1035^{* * *} \\
(0.0022)\end{array}$ & $\begin{array}{c}0.1035^{* * *} \\
(0.0022)\end{array}$ \\
\hline Central heating & & $\begin{array}{c}0.0959^{* * *} \\
(0.0033)\end{array}$ & $\begin{array}{c}0.0746^{* * *} \\
(0.0013)\end{array}$ & $\begin{array}{c}0.0829 * * * \\
(0.0025)\end{array}$ & $\begin{array}{c}0.0829 * * * \\
(0.0025)\end{array}$ & $\begin{array}{c}0.0826^{* * *} \\
(0.0025)\end{array}$ \\
\hline Listed & & $\begin{array}{c}0.2398 * * * \\
(0.0288)\end{array}$ & $\begin{array}{c}0.0604^{* * *} \\
(0.0055)\end{array}$ & $\begin{array}{c}0.0773^{* * *} \\
(0.0112)\end{array}$ & $\begin{array}{c}0.0774^{* * *} \\
(0.0112)\end{array}$ & $\begin{array}{c}0.0769^{* * *} \\
(0.0111)\end{array}$ \\
\hline Construction year 1945-1959 & & $\begin{array}{c}-0.0810^{* * *} \\
(0.0118)\end{array}$ & $\begin{array}{c}-0.0218^{* * *} \\
(0.0022)\end{array}$ & $\begin{array}{c}-0.0078 \\
(0.0047)\end{array}$ & $\begin{array}{l}-0.0077 \\
(0.0047)\end{array}$ & $\begin{array}{l}-0.0078^{*} \\
(0.0047)\end{array}$ \\
\hline Construction year 1960-1970 & & $\begin{array}{c}-0.1504^{* * *} \\
(0.0126)\end{array}$ & $\begin{array}{c}-0.0328^{* * *} \\
(0.0024)\end{array}$ & $\begin{array}{l}-0.0083 \\
(0.0056)\end{array}$ & $\begin{array}{c}-0.0082 \\
(0.0056)\end{array}$ & $\begin{array}{l}-0.0083 \\
(0.0056)\end{array}$ \\
\hline Construction year 1971-1980 & & $\begin{array}{c}-0.1565^{* * *} \\
(0.0118)\end{array}$ & $\begin{array}{c}-0.0010 \\
(0.0024)\end{array}$ & $\begin{array}{c}0.0242^{* * *} \\
(0.0056)\end{array}$ & $\begin{array}{c}0.0242^{* * *} \\
(0.0056)\end{array}$ & $\begin{array}{c}0.0242^{* * *} \\
(0.0056)\end{array}$ \\
\hline Construction year 1981-1990 & & $\begin{array}{c}-0.0829 * * * \\
(0.0118)\end{array}$ & $\begin{array}{c}0.0371^{* * *} \\
(0.0027)\end{array}$ & $\begin{array}{c}0.0647^{* * *} \\
(0.0060)\end{array}$ & $\begin{array}{c}0.0648^{* * *} \\
(0.0060)\end{array}$ & $\begin{array}{c}0.0647^{* * *} \\
(0.0060)\end{array}$ \\
\hline Construction year 1991-2000 & & $\begin{array}{c}0.0028 \\
(0.0122)\end{array}$ & $\begin{array}{c}0.1058^{* * *} \\
(0.0037)\end{array}$ & $\begin{array}{c}0.1341^{* * *} \\
(0.0068)\end{array}$ & $\begin{array}{c}0.1342^{* * *} \\
(0.0068)\end{array}$ & $\begin{array}{c}0.1340^{* * *} \\
(0.0068)\end{array}$ \\
\hline Construction year $\geq 2000$ & & $\begin{array}{c}0.0398^{* * *} \\
(0.0126)\end{array}$ & $\begin{array}{c}0.1513^{* * *} \\
(0.0042)\end{array}$ & $\begin{array}{c}0.1881^{* * *} \\
(0.0095)\end{array}$ & $\begin{array}{c}0.1881^{* * *} \\
(0.0095)\end{array}$ & $\begin{array}{c}0.1879 * * * \\
(0.0095)\end{array}$ \\
\hline Housing characteristics (16) & No & Yes & Yes & Yes & Yes & Yes \\
\hline Year and month fixed effects (37) & Yes & Yes & Yes & Yes & Yes & Yes \\
\hline PC6 fixed effects & No & No & Yes & Yes & Yes & Yes \\
\hline Only obs. $\leq 3 \mathrm{~km}$ of wind turb. in 2012 & No & No & No & Yes & Yes & Yes \\
\hline Number of observations & $2,219.088$ & $2,219,088$ & $2,219,088$ & 357,745 & 357,745 & 357,745 \\
\hline Adjusted $R^{2}$ & 0.3632 & 0.7381 & 0.9243 & 0.9231 & 0.9232 & 0.9232 \\
\hline
\end{tabular}

Note: The indicator 'wind turbine $\leq 2 \mathrm{~km}$ ' is one the first time a wind turbine is constructed (year of construction and all subsequent years) within two km of a property. Clustered (PC4) standard errors are in parentheses. *,**, ***, 10\%, 5\%, $1 \%$ significance, respectively. 
effects and adjustment effects are important and the effect is not immediate, the average treatment effect will also be an underestimate. Anticipation and adjustment effects will be discussed in Section V.C.

Finally, the effects of the control variables on house prices are plausible and have the expected signs once we include PC6 fixed effects and, hence, control for time-invariant spatial unobservables that are likely correlated with housing characteristics. Larger houses are more expensive. Detached houses are much more expensive than apartments, semidetached and terraced houses. Well-maintained properties and properties with central heating also have higher house prices.

\section{B. The impact radius}

Up to now, we used a cut-off value of two $\mathrm{km}$ to examine the treatment effect. To verify whether this is a valid choice, we let the treatment effect depend on distance, see equation (4). In particular, we include a set of dummy variables for each 250 meter (up to $2.5 \mathrm{~km}$ ) and compare the results relative to those observations outside a $2.5 \mathrm{~km}$ radius but still within a three $\mathrm{km}$ radius. ${ }^{18}$ Figure 4 reports the results (see Table 4 , column (5) for

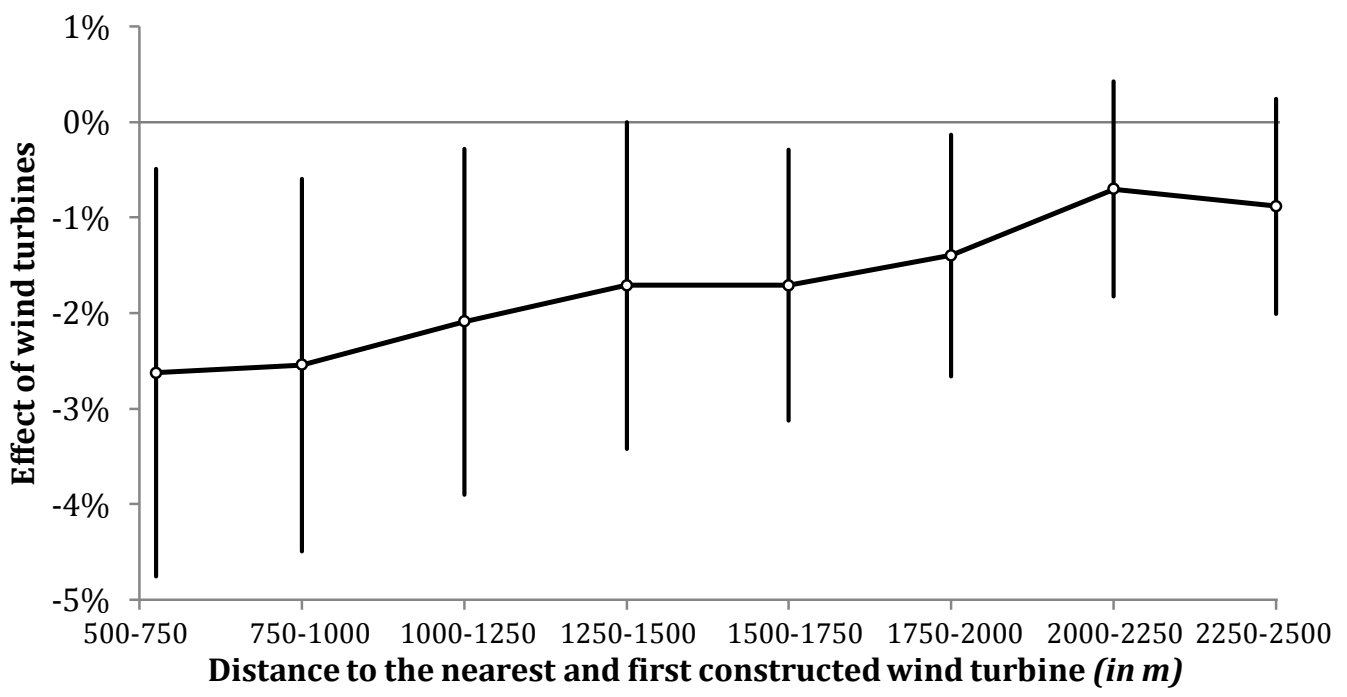

FIGURE 4 - DISTANCE PROFILE TREATMENT EFFECT

Notes: The dots represent conditional averages for a given distance band (e.g. 500$750 \mathrm{~m}, 750-1000 \mathrm{~m}$, etc.). The vertical lines represent 95 percent confidence intervals. The reference category consists of houses that are located further away than $2.5 \mathrm{~km}$ (but within three $\mathrm{km}$ ) of a wind turbine. The effect for the category $<500$ is not depicted, the effect is positive, small, and statistically insignificant.

${ }^{18}$ We also tried to use a three to five $\mathrm{km}$ radius as control group (the price effect for this category is more likely to be zero), which resulted in the same cut-off value for $d$. 
the coefficient estimates of the control variables). ${ }^{19}$

Figure 4 shows that the treatment effect is -2.6 percent at a $500-750 \mathrm{~m}$ distance from a turbine and it gradually decreases to about -1.4 percent at $1750-2000 \mathrm{~m}$, after which the effect becomes smaller than one percent and statistically insignificant at the five percent significance level. The effect below 500m (not reported) is positive, small, and statistically insignificant (it has a very large confidence interval), most likely due to the low number of observations in this category. The results in Figure 4 suggest that most of the previously estimated average treatment effect is the result of a relatively high number of observations further away from wind turbines (see Figure 3). This is also evident by the smaller confidence intervals in Figure 4 as distance to the nearest wind turbine increases. The results do not necessarily imply that there is no effect after a two $\mathrm{km}$ distance from a turbine, but that the effect is most likely so small that, on average, we cannot reject the null hypothesis that there is no effect. As such, we decided to use a two km radius as the relevant treatment area throughout this study. However, in Section V.D, we will show some results using different sizes of the treatment and control area.

\section{Anticipation and adjustment effects}

House prices may already decrease before a wind turbine becomes operational. It might also be the case that housing markets slowly incorporate new information, leading to adjustment effects in prices after the construction of a wind turbine. We, therefore, estimate a model which decomposes the treatment effect before and after the construction of a wind turbine, see equation (5). Figure 5 reports the results, again in percentages. The coefficients of the control variables are reported in Table 2, column (6).

The results in Figure 5 indicate that anticipation effects are indeed important. House prices are already statistically significantly lower (1.7 percent) two to three years before the placement of a wind turbine. After that, the effect on house prices is stable, about -2.0 percent, until after two years the effect starts declining to about -3.6 percent four to five years after construction. After five years the effect is estimated to be -2.3 percent. Hence, there seems to be some evidence that house prices adjust after the construction of a wind turbine. However, we cannot reject that the coefficient estimates after construction are statistically significantly different from each other ( $F$-value of 0.14$)$. In sum, the results suggest that if we take into account anticipation and adjustment effects the effect of wind

\footnotetext{
${ }^{19}$ We also employed a less flexible approach by including distance and distance squared in the regression model. Since the effect turns out to be very local, we get a very steep gradient and unrealistic results if we measure the price effect without any restriction on distance. As such, we decided to use a cut-off value $d$ and a (close to) non-parametric approach to measure the effect of distance.
} 


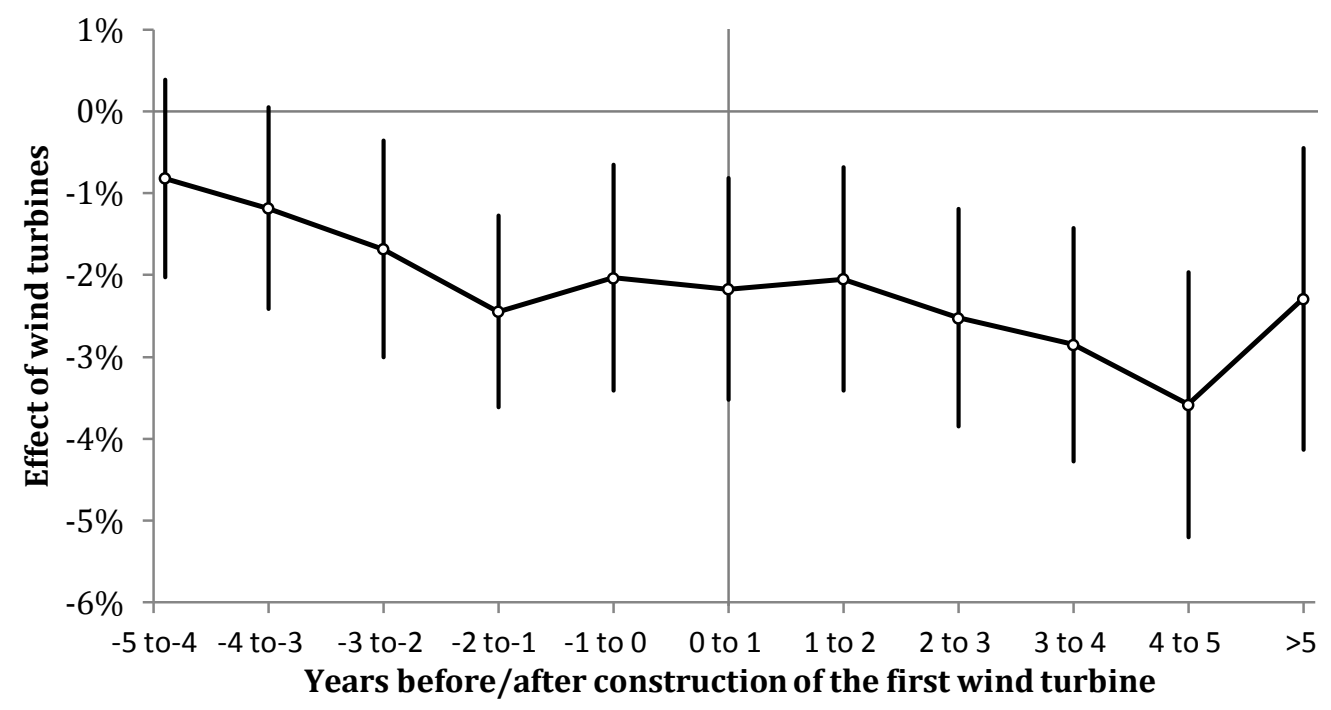

FIGURE 5 -ANTICIPATION AND ADJUSTMENT EFFECTS

Notes: The dots represent conditional averages for a given year before/after the construction of the first wind turbine within a two km radius of a property (e.g. 0-1 is the year of construction). The vertical lines represent 95 percent confidence intervals. The reference category consists of houses that are located further away than two $\mathrm{km}$ of a wind turbine or houses that are more than five years before the placement of the first wind turbine within a two km radius.

turbines is substantially higher than the baseline estimate of -1.4 percent (see Table 4 , column (4)). ${ }^{20}$

\section{Identification revisited}

To identify the causal effect of wind turbines on house prices, we included PC6 fixed effects and only used observations that are within three $\mathrm{km}$ of a wind turbine in 2012. The identifying assumption is that unobservable time-varying factors are not correlated to the treatment effect. To investigate the validity of this assumption in more detail, we have done several robustness checks. The results are reported in Table 5.

First, there may be unobserved PC6 time trends or municipality time trends that are not captured by the year fixed effects but are correlated with the treatment effect. Because our

${ }^{20}$ We also estimated a response function that captures effects until ten years after the construction of a wind turbine to examine in more detail possible rebound effects. It might for instance be that households get used to living close to a wind turbine (learning) or there is some underlying sorting effect going on. We find a similar pattern of decline and increase as depicted in Figure 5. After four to five years the treatment effect steadily declines until it stabilizes at $-2 \%$. Again, we cannot reject the possibility that the effect after construction is just a horizontal line, also not using the full transaction dataset or after imposing functional form restrictions (e.g. fractional polynomial, spline). 
TABLE 5 - IDENTIFICATION AND CONTROL GROUPS (DEPENDENT VARIABLE: THE LOGARITHM OF HOUSE PRICE)

\begin{tabular}{|c|c|c|c|c|c|c|c|c|}
\hline & (1) & $(2)$ & (3) & (4) & (5) & $(6)$ & (7) & $(8)$ \\
\hline & $\begin{array}{l}\text { PC6×decade } \\
\text { fixed effects }\end{array}$ & $\begin{array}{l}\text { Municipality } \times \\
\text { year trends }\end{array}$ & $\begin{array}{l}\text { Repeat } \\
\text { sales }\end{array}$ & $\begin{array}{c}\text { Only obs. } \\
\leq 2 \mathrm{~km} \text { and } 3-5 \mathrm{~km}\end{array}$ & $\begin{array}{l}3 \mathrm{~km} \text { circle, } 3-5 \mathrm{~km} \\
\text { control group }\end{array}$ & $\begin{array}{l}\text { Only obs. } \\
\leq 2 \mathrm{~km}\end{array}$ & $\begin{array}{c}\text { Only obs. in } \\
\text { wind plan areas }\end{array}$ & $\begin{array}{l}\text { Only obs. } \leq 3 \mathrm{~km} \& \\
\text { in wind plan areas }\end{array}$ \\
\hline Wind turbine $\leq 2 \mathrm{~km}$ & $\begin{array}{c}-0.0080^{* *} \\
(0.0040)\end{array}$ & $\begin{array}{c}-0.0119^{* * *} \\
(0.0041)\end{array}$ & $\begin{array}{c}-0.0195^{* * *} \\
(0.0067)\end{array}$ & $\begin{array}{c}-0.0233^{* * *} \\
(0.0075)\end{array}$ & $\begin{array}{c}-0.0184^{* * *} \\
(0.0056)\end{array}$ & $\begin{array}{l}-0.0096^{+} \\
(0.0059)\end{array}$ & $\begin{array}{c}-0.0151 \\
(0.0163)\end{array}$ & $\begin{array}{l}-0.0320^{+} \\
(0.0196)\end{array}$ \\
\hline Housing characteristics (16) & Yes & Yes & Yes & Yes & Yes & Yes & Yes & Yes \\
\hline Year and month fixed effects (37) & Yes & Yes & Yes & Yes & Yes & Yes & Yes & Yes \\
\hline PC6 fixed effects & Yes & Yes & No & Yes & Yes & Yes & Yes & Yes \\
\hline PC6×decade fixed effects & Yes & No & No & No & No & No & No & No \\
\hline Municipality×year trends & No & Yes & No & No & No & No & No & No \\
\hline Obs. $\leq 3 \mathrm{~km}$ of wind turbine in 2012 & Yes & Yes & Yes & No & Yes & No & No & Yes \\
\hline Obs. $\leq 2 \mathrm{~km}$ of wind turbine in 2012 & Yes & Yes & Yes & Yes & Yes & Yes & No & Yes \\
\hline Obs. $3-5 \mathrm{~km}$ of wind turbine in 2012 & No & No & No & Yes & Yes & No & No & No \\
\hline Obs. in wind plan area & No & No & No & No & No & No & Yes & Yes \\
\hline Number of observations & 357,745 & 357,745 & 60,890 & 544,897 & 752,703 & 149,936 & 5,606 & 2,685 \\
\hline Adjusted $R^{2}$ & 0.9296 & 0.9320 & 0.8385 & 0.9234 & 0.9229 & 0.9229 & 0.8903 & 0.9062 \\
\hline
\end{tabular}

Notes: The indicator 'wind turbine $\leq 2 \mathrm{~km}$ ' is one the first time a wind turbine is constructed (year of construction and all subsequent years) within two km of a property. Clustered (PC4) standard errors are in parentheses. ${ }^{+}, *, * *, * * *, 15 \%, 10 \%, 5 \%, 1 \%$ significance, respectively. 
data spans a long time period (more than 25 years), we might expect that most unobservable factors are changing over time. To address this issue, we control for PC6decade trends by including fixed effects for each PC6-decade combination (1985-1990, 1991-2000, 2001-2011). We also estimate a specification with municipality-specific linear time trends. The results are reported in Table 5, columns (1) and (2), respectively.

The results in column (1) indicate that the effect of wind turbines on house prices is -0.8 percent, but it is still statistically significant at the five percent significance level. That the effect is somewhat lower than our -1.4 base estimate (see Table 4, column 4), is not too surprising, given that part of the treatment effect is absorbed by the PC6×decade fixed effects. We also estimated a specification with municipality time trends. Column (2) suggest that after including those trends the treatment effect is still -1.2 percent. ${ }^{21}$

Second, although we have used a model with detailed location fixed effects as our main regression model, we also estimated the treatment effect using a repeat sales approach (first differences) to control for house-specific effects. Using repeat sales gives us a 'constant quality' estimate of the treatment effect. If the base model with PC6 fixed effects adequately controls for housing quality, we should not expect to see a large difference between the base estimate and the repeat sales estimate (assuming there is no sample selection bias as a result of using repeat sales). Column (3) shows that the repeat sales estimate is fairly close to the baseline estimate of -1.4 percent: the estimated treatment effect is -2.0 percent and statistically significant.

Third, as mentioned in Section V.A, we might underestimate the treatment effect if there is still an effect in the control group area (also see Figure 4, Section V.B). As such, instead of using a $2-3 \mathrm{~km}$ radius as the control group area we used those observations that are located between three and five $\mathrm{km}$ distance from a wind turbine in 2012. Further away from a wind turbine it is more reasonable to assume that the treatment effect is zero. Table 5, column (4) reports the results. The treatment effect becomes -2.3 percent, which is indeed higher than the baseline estimate of -1.4 percent. Alternatively, we also used a larger treatment area (three $\mathrm{km}$ radius). The regression estimates are shown in column (5). The treatment effect becomes a bit larger, about -1.8 percent. These results suggest that the baseline estimate of -1.4 percent (using a $2 \mathrm{~km}$ treatment area) is a somewhat conservative estimate.

Fourth, the estimates of the treatment effect have been based on the difference in trend of the control versus treatment group and the difference in timing of wind turbine construction. In column (6), we show estimates of the model that only uses observations within a two km radius of a wind turbines. That is, the treatment effect is identified using the difference in timing of wind turbine construction only. In this case, we find a treatment effect of about -1.0 percent, which is only significant at the 15 percent level ( $p$-value of

${ }^{21}$ Alternatively, the treatment coefficient itself might also be changing over time. We have estimated a model that allows the treatment effect to differ before/after the year 2000, by including an interaction effect, which appears to be statistically insignificant. 
0.101). Hence, although we cannot make strong statements, the results seem to support our initial findings as the point estimate is very similar to the baseline estimate.

Finally, one might argue that the locations in which the first generation wind turbines were placed (e.g. the north of the Netherlands) are considerably different from areas that have experienced a surge in the number of wind turbines more recently (e.g. Flevoland). If the unobserved traits are substantially different and these unobservable trends are correlated with the placement of wind turbines, our results may be biased. To address this issue, we use a recently announced plan to construct wind turbines in the Netherlands. In March 2014, the areas where future wind turbines are going to be placed were announced by the Dutch government. These areas are located in Groningen, Flevoland, and near the port area of Rotterdam (see Figure A1 in Appendix A) and likely have similar unobservable location characteristics. Column (7), Table 5, shows the estimate of the treatment effect where we only select observations located in those future wind turbine areas. The estimated treatment effect is -1.5 percent, which is in line with the baseline estimates, but statistically insignificant. Column (8) adds the additional restriction that only observations within a three $\mathrm{km}$ radius of a wind turbine in 2012 are included in the regression analysis. In this case, the number of observations decreases even more (to 2,570) and we find a treatment effect of -3.2 percent. This effect is statistically significant at the 15 percent significance level ( $p$-value of 0.113 ). These results show that our initial findings are reasonably robust in terms of sign and magnitude.

\section{E. Heterogeneity in the effect of wind turbines on house prices}

There is considerable heterogeneity in the treatment effect, for example, because wind turbines differ across locations (e.g. height, diameter of the blades). The number of wind turbines also differs across locations. Table 6 reports the results of several alternative specifications in which we include interaction effects to examine the heterogeneity in the treatment effect.

First, the treatment effect may depend on the number of wind turbines that are constructed. For example, wind parks are likely to have much stronger price effects than single wind turbines. As a result, we interacted the treatment effect dummy with the number of wind turbines within a two km radius at the time the first wind turbine was constructed. Of the 80,000 'treated' properties, 63 percent experienced the construction of a single wind turbine, 12 percent by two turbines, 8 percent by three turbines, 11 percent by four turbines, and the remaining 6 percent by five or more turbines. Table 5, column (1), reports the regression results including the interaction effects with the number of wind turbines. The coefficient estimates are not statistically significant at the five percent significance level. They are also not jointly significant (F-value of 1.41). These results 
TABLE 6 - HETEROGENEITY IN THE EFFECT OF WIND TURBINES ON HOUSE PRICES (Dependent variable: the logarithm of house price)

\begin{tabular}{|c|c|c|c|c|c|c|c|}
\hline & (1) & $(2)$ & (3) & $(4)$ & (5) & (6) & (7) \\
\hline & Multiple turbines & $\begin{array}{l}\text { Turbine } \\
\text { height }\end{array}$ & $\begin{array}{l}\text { Diameter of } \\
\text { the blades }\end{array}$ & $\begin{array}{l}\text { Height and } \\
\text { diameter }\end{array}$ & $\begin{array}{c}\text { Urban/rural } \\
\text { effect }\end{array}$ & Shadow & Direct view \\
\hline Wind turbine $\leq 2 \mathrm{~km}$ & $\begin{array}{c}-0.0185^{* * *} \\
(0.0064)\end{array}$ & $\begin{array}{c}-0.0151^{* * *} \\
(0.0057)\end{array}$ & $\begin{array}{l}-0.0113^{*} \\
(0.0059)\end{array}$ & $\begin{array}{c}-0.0125^{* *} \\
(0.0060)\end{array}$ & $\begin{array}{c}-0.0126^{* *} \\
(0.0059)\end{array}$ & $\begin{array}{c}-0.0142^{* *} \\
(0.0057)\end{array}$ & $\begin{array}{c}-0.0145^{* *} \\
(0.0057)\end{array}$ \\
\hline Wind turbine $\leq 2 \mathrm{~km} \times 2$ turbines & $\begin{array}{c}0.0097 \\
(0.0068)\end{array}$ & & & & & & \\
\hline Wind turbine $\leq 2 \mathrm{~km} \times 3$ turbines & $\begin{array}{c}0.0039 \\
(0.0095)\end{array}$ & & & & & & \\
\hline Wind turbine $\leq 2 \mathrm{~km} \times 4$ turbines & $\begin{array}{l}0.0312^{*} \\
(0.0172)\end{array}$ & & & & & & \\
\hline Wind turbine $\leq 2 \mathrm{~km} \times 5$ turbines & $\begin{array}{c}0.0181^{*} \\
(0.0105)\end{array}$ & & & & & & \\
\hline Wind turbine $\leq 2 \mathrm{~km} \times$ turbine $\geq 100 \mathrm{~m}$ & & $\begin{array}{c}-0.0221^{* *} \\
(0.0107)\end{array}$ & & $\begin{array}{c}0.0075 \\
(0.0129)\end{array}$ & & & \\
\hline Wind turbine $\leq 2 \mathrm{~km} \times$ diameter $\geq 90 \mathrm{~m}$ & & & $\begin{array}{c}-0.0371^{* * *} \\
(0.0104)\end{array}$ & $\begin{array}{c}-0.0327^{* * *} \\
(0.0110)\end{array}$ & & & \\
\hline Wind turbine $\leq 2 \mathrm{~km} \times$ urban area & & & & & $\begin{array}{l}-0.0043 \\
(0.0098)\end{array}$ & & \\
\hline Wind turbine $\leq 2 \mathrm{~km} \times$ shadow area & & & & & & $\begin{array}{l}-0.0247 \\
(0.0179)\end{array}$ & \\
\hline Wind turbine $\leq 2 \mathrm{~km} \times$ direct view & & & & & & & $\begin{array}{c}0.0261 \\
(0.0201)\end{array}$ \\
\hline Housing characteristics (16) & Yes & Yes & Yes & Yes & Yes & Yes & Yes \\
\hline Year and month fixed effects (37) & Yes & Yes & Yes & Yes & Yes & Yes & Yes \\
\hline PC6 fixed effects & Yes & Yes & Yes & Yes & Yes & Yes & Yes \\
\hline Only obs. $\leq 3 \mathrm{~km}$ of wind turbine in 2012 & Yes & Yes & Yes & Yes & Yes & Yes & Yes \\
\hline Number of observations & 357,745 & 319,796 & 357,058 & 319,270 & 357,745 & 357,745 & 357,745 \\
\hline Adjusted $R^{2}$ & 0.9232 & 0.9245 & 0.9233 & 0.9247 & 0.9231 & 0.9231 & 0.9231 \\
\hline
\end{tabular}

Note: Wind turbine $\leq 2 \mathrm{~km}$ is one the first time a wind turbine is constructed (year of construction and all subsequent years) within two km of a property. Clustered (PC4) standard errors are in parentheses. ${ }^{*}, * *, * *, 10 \%, 5 \%, 1 \%$ significance, respectively. 
suggest that a single wind turbine that pollutes the landscape is as polluting as multiple wind turbines. ${ }^{22}$

Second, we would expect to find that wind turbines that are taller are visually less appealing and, as such, the negative treatment effect on house prices is larger for those turbines. To test this hypothesis, we include an interaction term of the treatment dummy and a dummy that indicates whether the axis height of the turbine is equal or larger than 100 meters (about 2.8 percent of the onshore wind turbines). Note that we lose some observations because the axis height is missing in some cases. Table 5, column (2), reports the regression estimates. We find that for turbines that are relatively tall there is an additional negative effect on house prices of -2.2 percent on top of the -1.5 percent treatment effect for the reference category (i.e. turbines lower than 100 meters).

Third, we also include an interaction effect based on the diameter of the blades, expecting that turbines with larger blades impose larger negative externalities. Besides the fact that such a turbine might have a more detrimental effect on the landscape, shadow and flickering are mainly determined by the size of the blades (i.e. not the mast of the turbine itself). We distinguish between those turbines with blades smaller and larger than 90 meters. About 9.2 percent of the turbines have blades larger than or equal to 90 meters. The results are reported in column (3). We find that turbines with relatively large blades have a 3.7 percent additional negative effect on house prices.

One particular concern is that those turbine that are tall also have large blades. In particular, the correlation between the height of a turbine and the diameter of its blades is 0.79 . This suggests that it is very difficult to separately identify the effect of height versus diameter of the blades. Nevertheless, in column (4) we included both the indicator for turbine height and diameter of the blades. The results in column (4) suggest that it is mainly the diameter of the blades that affects house prices, rather than the axis height.

Fourth, most of the turbines may be located in rural areas, to potentially avoid large negative external effects. It might be argued that the marginal price effect of a wind turbine in an urban area is larger, because open space is valued higher. Hence, the opportunity costs of constructing a wind turbine may be higher. To examine whether this is indeed the case, we include an interaction effect between the treatment effect and an indicator whether an area is classified as urban. We consider houses that are located in areas with more than five thousand persons per square kilometer as urban areas (45 percent of observations). Column (5) shows that the effect of wind turbines on house prices is not statistically significantly different between urban and rural areas. However, note that the total negative

22 The number of wind turbines within a two km radius of a house might change over time. We also examined the interaction effect with a time-varying measure of wind turbines. The results are virtually the same. It might also be that wind turbines are placed successively closer to a property. If we exclude those properties (303 transactions), we still find a treatment effect of -1.4 percent. 
external effect in urban areas is likely higher because there are more properties affected by the placement of a wind turbine.

Fifth, there may be direct effects of shadow and view. To proxy for the effects of shadow, we take into account that the Netherlands is located to the north of the equator. As such, only houses in the northern half of each two km circle around a turbine are potentially in the shadow of a wind turbine sometime during the day. The shadow area is then defined as twelve times the diameter of the blades of a wind turbine on the northern part of each wind turbine. Only 0.65 percent of the 80,000 houses that are within two $\mathrm{km}$ after the placement of a turbine are in a shadow area. Table 6, column (6), reports the regression estimates where we include the interaction effect with the 'shadow area' indicator. Although we find a negative effect of 2.5 percent, the effect of wind turbine shadow on house prices is not statistically significantly different from zero. This does not imply that there is no effect of wind turbine shadow on house prices but that, even with the quality of data used in this study, we cannot precisely estimate its effect.

Finally, we also tried to estimate the effect of direct view on a wind turbine. We use additional information on all buildings in 2011 in the Netherlands obtained from the BAG register (in Dutch: 'Basisadministratie Adresgegevens en Gebouwen'). Following Koster et al. (2014), we calculate for each property a line of sight from the centroid of each property to the nearest wind turbine and examine whether this line of sight is obstructed by any buildings. If the line of sight is obstructed by other houses, we assume that there is no direct view (but still indirect view). According to this measure of direct view, only 0.69 percent of the treated 80,000 houses have a direct view on a wind turbine. The estimated effect of direct view is reported in column (7). The effect seems to be positive, rather than negative, but it is statistically insignificant. ${ }^{23}$

\section{F. Counterfactual analysis}

In this subsection, we carry out a counterfactual analysis to gain a better understanding of the quantitative implications of our empirical results. We would like to stress that the results should be interpreted with caution, as we have to make several simplifying assumptions to estimate the total external costs of wind turbines. First, we know that the transactions data we use only covers about 70 percent of all transactions, so we multiply the estimate for the owner-occupied market by $100 / 70$ to obtain an estimate for the full owneroccupied market. We assume that this share is the same across the Netherlands and stable over time. Second, about 55 percent of the properties are owner-occupied. To get an estimate for the full market, including rental housing, we add 45 percent to the total owner-

${ }^{23}$ The direct view indicator is at best a very noisy indicator. For example, buildings are not always of the same height, windows may not be on every side of the house and views may also be obstructed by other objects (e.g. trees, walls). In addition, we only measured the line of sight to the nearest wind turbine. 


\begin{tabular}{|c|c|c|c|c|}
\hline \multirow[b]{2}{*}{ Assumed price effect } & \multicolumn{2}{|c|}{$\begin{array}{c}\text { Owner-occupied } \\
\text { houses }\end{array}$} & \multicolumn{2}{|c|}{ All houses } \\
\hline & $1.4 \%$ & $2.3 \%$ & $1.4 \%$ & $2.3 \%$ \\
\hline Total loss ( $€$, in millions) & 403 & 642 & 733 & 1,167 \\
\hline Total loss / house $(€)$ & 3,500 & 5,600 & 3,500 & 5,600 \\
\hline Total loss / wind turbine $(€)$ & 224,000 & 356,000 & 407,000 & 645,000 \\
\hline Total loss / wind turbine / year $(€)$ & 11,200 & 17,800 & 20,300 & 32,400 \\
\hline Total loss / average construction costs (in \%) & 14.0 & 22.3 & 25.4 & 40.5 \\
\hline
\end{tabular}

occupied market estimate. We assume that the effect of wind turbines for rental houses is identical to those of owner-occupied housing and that the share of rental houses is similar across the Netherlands. The latter assumption is somewhat problematic, because the share of rental housing tends to be higher in urbanized parts of the Netherlands, where fewer wind turbines are placed. If this is true, our calculations will deliver upper bounds of the total effects of wind turbines. We therefore will also report estimates where we only take into account owner-occupied housing. Third, we use a price index (i.e. the coefficients on the year fixed effect from our baseline estimate reported in Table (4), column (4)) to update the price of an affected house to the year 2011. This price index does not differ across locations or types of houses.

Table 7 reports the back-of-the-envelope calculations of the total implied external economic costs that have capitalized in housing values due to the placement of wind turbines. We consider two price effects: a conservative price effect of 1.4 percent, which is in line with the baseline estimate reported in Table 4, column (4). We also estimate the external costs when we assume a less conservative price effect of 2.3 percent, which is in line with the cumulative effect when we take into account anticipation and adjustment effects, see Figure 5.

The total loss in house value is 226 million Euros if we multiply the average treatment effect of -1.4 percent by the first transaction price after a house is 'treated' and sold. If we correct for house price appreciation (2011 is the base year), the total loss is 282 million Euros. Hence, multiplying by $100 / 70$, the total loss for all owner-occupied houses is about 403 million Euros. This is about 3,500 Euros per 'treated' house, 224,000 euros per wind turbine (i.e. there are 1,802 turbines on land) or 11,200 Euros per wind turbine per year (assuming a life span of 20 years). If we use -2.3 percent as the treatment effect the total effect is 642 million Euros, about 5,600 Euros per affected house, and about 356,000 euros per wind turbine. Even though the marginal effect for each house is not large, the total external costs of wind turbines are quite substantial because house prices are in nominal 
terms quite high and relatively a lot of houses have been treated (i.e. 79,912 houses in our sample, 114,160 houses for the whole owner-occupied market). The total loss in house value taking into account rental housing ranges between 733 million Euros $(-1.4$ percent treatment effect) and 1,167 million Euros ( -2.3 percent treatment effect). The total loss per house remains of course the same (between 3,500 and 5,600 Euros). Per wind turbine the estimate increases to 407,000 Euros and 645,000 Euros, respectively, which is between 20,300 Euros and 32,400 Euros per wind turbine/year. Given that the average (onshore) wind turbine produces about 1.2 megawatts, and assuming 1,325 Euros construction costs per $\mathrm{kW}$ installed capacity (ECN, 2008), the average construction cost is about 1.6 million Euros. As a result, we find that the external cost per wind turbine is between 14.0 percent $(-1.4$ percent treatment effect and only owner-occupied housing) and 40.5 percent $(-2.3$ percent treatment effect and all housing) of its average construction cost.

Besides the decrease in house value, wind turbines also reduce $\mathrm{CO} 2$ emissions. Based on data from Statistics Netherlands, the $\mathrm{CO} 2$ reduction as a result of wind turbines placed on land ranges between 36 kton in 1990 to 2,442 kton in 2012. Between 1990 and 2012 the total $\mathrm{CO} 2$ reduction is about 20,500 kton. Although estimates vary, if we assume that the value of one ton CO2 reduction in 2011 is worth about 15 to 50 Euros (abatement cost, see Marcantonini and Ellerman, 2013), the total CO2 benefits have been 310 to 1,025 million Euros. This is about as large as the total decrease in house value as a result of wind turbine construction. The main issue, however, is that the $\mathrm{CO} 2$ reduction benefits of wind turbines accrue to the whole world's population, but that the external costs in terms of house value are spatially clustered and, as such, are paid by a specific group of homeowners. Economic theory suggests that, much like the fact that the costs of $\mathrm{CO} 2$ pollution should be internalized by those who pollute, the external costs of wind turbines in terms of decreases in house value should be taken into account by those who own wind turbines.

In sum, although it is apparent that there are quite some assumptions behind the estimates reported in this section, it does suggest that the total loss in house value in the Netherlands as a result of wind turbine construction is substantial. Moreover, we conclude that the external costs of a wind turbine are at least 10 percent of its construction costs.

\section{Conclusion}

This paper has investigated the effect of wind turbines on house prices. The results show a pronounced negative external effect of the construction of wind turbines on house prices. Our most conservative estimate suggests a negative price effect of 1.4 percent on average after the construction of a wind turbine within a two $\mathrm{km}$ distance from a property. The negative effect ranges from 1.4 to 2.6 percent, depending on the distance to the turbine. We also show that anticipation effects are important: house prices start to decrease about three years before a nearby wind turbine becomes operational. The total effect is -2.3 percent. We calculate that, given a range of assumptions, the external costs of a wind turbine are at least 
10 percent of its construction costs. We argue that these costs should be taken into consideration when building wind turbines close to urban areas.

Given our finding of a local (two km) external effect of wind turbines on house prices, the results in this paper imply that the external effect can be largely avoided by constructing wind turbines further away from urbanized areas. A concern is whether this is possible in a densely populated country as the Netherlands. An alternative is to construct offshore wind parks, but this is still very costly. It might therefore be the case that the external costs of onshore wind turbines offset the additional costs of constructing offshore wind turbines. An option would be to coordinate the placement of wind turbines not at a national level, but a supranational one and to place wind turbines in those locations where the opportunity costs are lowest (e.g. low density areas). Another business strategy that is currently being implemented in the Netherlands is that homeowners can become a shareholder of a wind turbine. This potentially increases the (local) support for the placement of wind turbines. It can also partly compensate homeowners for the loss in house value as a result of wind turbine construction.

Finally, it is important to recognize that many wind turbines are placed in rural areas. This, however, does not mean that such turbines have no external economic effects. In particular, the value of nearby land is expected to decrease since the option value of the land decreases (i.e. no houses are allowed to be constructed very close to wind turbines). Future research should, therefore, also focus on the effect of wind turbines on the value of nearby land.

\section{References}

Carter, J. 2011. The Effect of Wind Farms on Residential Property Values in Lee County, Illinois, Preliminary draft, Spring 2011, Illinois State University.

Case, K.E., Shiller, R.J., 1989. The Efficiency of The Market for Single-Family Homes. American Economic Review 79, 125-137.

Dooper, J., Hulst, F. van der, Rijn, R. van, 2010. Windenergie in Utrecht haalbaarheidsstudie, Bosch \& Van Rijn, consultants in renewable energy and planning.

European Commission, 2013. Renewable Energy Progress Report. European Commission, 27-03-2013, Brussels.

ECN, 2008. Technisch-economische Parameters van Duurzame Energieopties in 2009-2010, Eindadvies basisbedragen voor de SDE-regeling. Policy report, ECN-E--08-090.

Gatzlaff, D.H., Haurin, D.R., 1998. Sample Selection and Biases in Local House Value Indices, Journal of Urban Economics 27, 199-222.

GWEC, 2012. Global Wind Report, Annual Market Update 2012, Brussels, Belgium.

Gibbons, S., 2014. Gone With the Wind: Valuing the Local Impacts of Wind Turbines Through House Prices. LSE-SERC Discussion paper 159. 
Hoen, B., Wiser, R., Cappers, P., Thayer, M., Sethi, B., 2010. Wind Energy Facilities and Residential Properties: The Effect of Proximity and View on Sales Prices, American Real Estate Society Annual Conference, Naples, Florida, 14-17 April 2010.

IEA, 2012. World Energy Outlook 2012, Chapter 7, Renewable Energy Outlook, OECD/IEA, Paris, France.

IEA, 2013. CO2 Emissions from Fuel Combustion Highlights (2013 Edition), OECD/IEA, Paris, France.

Koster, H.R.A., Van Ommeren, J.N., Rietveld, P., 2014. Historic Amenities, Income and Sorting of Households,. Accepted for publication in Journal of Economic Geography.

Ladenburg, J., Dubgaard, A., 2007. Willingness to Pay for Reduced Visual Disamenities from Offshore Wind Farms in Denmark, Energy Policy 35, 4059-4071.

Marcantonini, C., Ellerman, A.D., 2013. The Cost of Abating CO2 Emissions by Renewable Energy Incentives in Germany, MIT CEEPR WP 2013-005.

McMillen, D.P., McDonald, J., 2004. Reaction of House Prices to a New Rapid Transit Line: Chicago's Midway Line, 1983-1999, Real Estate Economics 32, 463-486.

NRC, 2013. Miljoenenclaim Bewoners Houten na Plaatsen Windmolens [Million Claim Inhabitants Houten After Construction Wind Turbines]. Dutch newspaper article from NRC, 29 Oktober 2013.

Redfearn, C.L., 2009. How Informative are Average Effects? Hedonic Regression and Amenity Capitalisation in Complex Urban Housing Markets, Regional Science and Urban Economics 39: 297306.

SER, 2013. Energieakkoord voor duurzame groei, Sociaal-Economische Raad, The Hague.

Sims, S., Dent, P., Oskrochi, R., 2008. Modelling the Impact of Wind Farms on House Prices in the UK, International Journal of Strategic Property Management 12, 251-269.

Trouw, 2013. Vechten Tegen Windmolens [Fighting against wind turbines], Dutch newspaper article from Trouw, 29 October 2013.

Van Ommeren, J.N., Wentink, D., 2011. The (Hidden) Cost of Employer Parking Policies, International Economic Review 53, 965-978.

Wheaton, W.C., 1990. Vacancy, Search, and Prices in a Housing Market Matching Model, Journal of Political Economy 98, 1270-1292. 
Appendix A. Future wind turbine areas

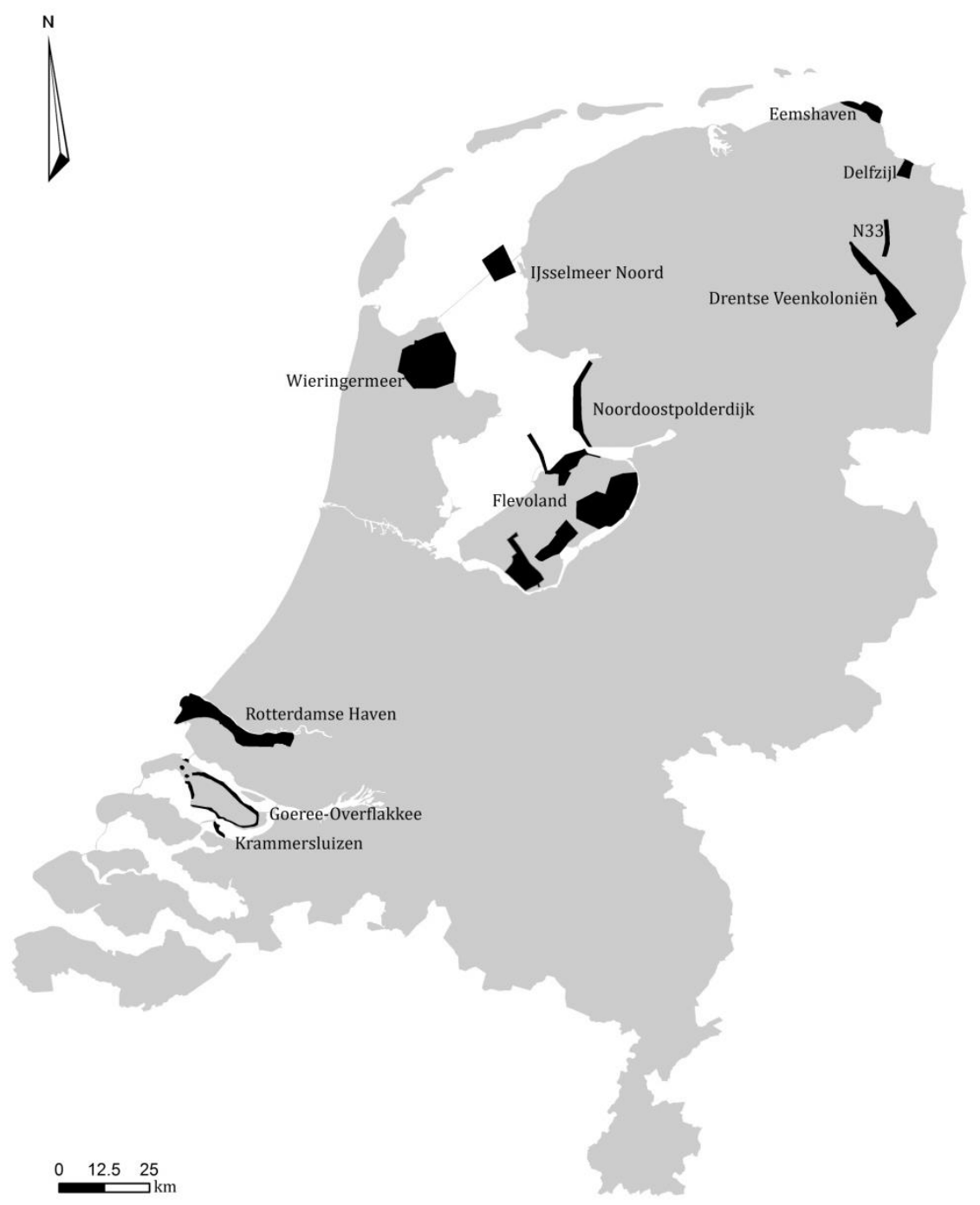

FigURE A1 - DESIGNATED AREAS WHERE FUTURE WIND TURBINES WILL BE PLACED Source: Trouw, October 29, 2014. 